\title{
The clinical management of neuropathic pain
}

\author{
Dwight E Moulin MD FRCP(C) Neurology
}

\begin{abstract}
DE Moulin. The clinical management of neuropathic pain. Pain Res Manage 2006;11(Suppl A):30A-36A.

Chronic neuropathic pain as a result of injury to the central or peripheral nervous system is common in clinical practice, and is especially predominant in the elderly. The present review summarizes the epidemiology, clinical features, pathophysiology, differential diagnosis and management of neuropathic pain and specifically details an evidence-based approach to the pharmacological treatment of this disabling condition. Preventive strategies and novel treatment approaches are required to improve the management of neuropathic pain.
\end{abstract}

\section{Prise en charge clinique de la douleur neuropathique}

\begin{abstract}
La douleur neuropathique secondaire à des lésions du système nerveux central ou du système nerveux périphérique s'observe fréquemment en pratique clinique, surtout chez les personnes âgées. Le présent article passe en revue l'épidémiologie, les aspects cliniques, la physiopathologie, le diagnostic différentiel et le traitement de la douleur neuropathique, et expose en détail une approche du traitement médicamenteux de cette maladie invalidante, fondée sur des preuves. Des stratégies de prévention et de nouvelles thérapies s'imposent pour améliorer la prise en charge de la douleur neuropathique.
\end{abstract}

Key Words: Neuropathic pain; Pharmacological management

$\mathrm{N}$ europathic pain is defined by the International Association for the Study of Pain as pain "initiated or caused by a primary lesion or dysfunction in the nervous system" (1). Neuropathic pain is a challenging clinical problem, because it is usually persistent, severe and resistant to conventional analgesics such as nonsteroidal anti-inflammatory drugs (2). It can be caused by lesions of the peripheral or central nervous system, or both. Sensory nerve injury usually results in numbness and sensory deficit in the territory of the involved nerve. Fortunately, pain is an unusual manifestation of nerve injury and there are few predictors to indicate which patients will develop this complication. For instance, $50 \%$ of diabetic patients develop neuropathy during the course of their illness, but only approximately $10 \%$ report actual dysesthesias or pain (3). Similarly, breast surgery with transection of the intercostal brachial nerve results in neuropathic pain in only $20 \%$ of patients (4).

Prevalence estimates suggest that $1 \%$ to $2 \%$ of Americans suffer from neuropathic pain, which suggests that at least half a million Canadians have this disabling condition $(5,6)$. However, the prevalence of neuropathic pain is increasing because the population is aging, and several neuropathic pain syndromes, including diabetic neuropathy and postherpetic neuralgia, are more common in elderly patients. In addition, cancer patients are living longer (7) and many of the treatments used in the management of cancer, including chemotherapy, can cause neuropathic pain.

\section{CLINICAL FEATURES AND PATHOPHYSIOLOGY OF NEUROPATHIC PAIN}

The clinical features of neuropathic pain can be divided into spontaneous pain and stimulus-evoked pain. These sensations usually arise from the territory of the injured nerve, but they can radiate into adjacent, normally innervated, areas. Spontaneous pain is commonly described as burning, icy, or intense tightness with superimposed shooting or lancinating pain. Stimulus-evoked pain includes allodynia, which is pain in response to a normally nonpainful stimulus, and hyperalgesia, defined as increased pain in response to a normally painful stimulus. Various forms of allodynia can be demonstrated in the clinical setting. Dynamic allodynia can be elicited by flicking one or more hairs on the skin surface. Thermal allodynia can be demonstrated by applying an ice cube to the affected area - the paradoxical sensation of heat or burning is a classical feature of nerve injury. Repeated mechanical stimuli such as light touch may build into an explosive pain over several seconds and radiate beyond the territory of the injured nerve. These features illustrate temporal and spatial summation of the stimulus and this is referred to as hyperpathia. Superimposed autonomic features, such as alterations in temperature, colour and sweating, and the development of trophic changes, provide a diagnosis of reflex sympathetic dystrophy or complex regional pain syndrome (8).

Departments of Clinical Neurological Sciences and Oncology, Earl Russell Chair Pain Research, University of Western Ontario; Pain and Symptom Management, London Regional Cancer Program, London, Ontario

Correspondence: Dr Dwight Moulin, London Regional Cancer Program, 790 Commissioners Road East, London, Ontario N6A 4 L6.

Telephone 519-685-8661, fax 519-685-8636, e-mail dwight.moulin@lhsc.on.ca 
There are several mechanisms responsible for pain following nerve injury, and they are based on peripheral and central sensitization of the nervous system $(9,10)$. After peripheral nerve injury, sodium channels accumulate along the length of the axon, at sites of neuroma formation and in the dorsal root ganglia. These sodium channels are hyperexcitable and are the foci of ectopic impulse formation. In addition to firing spontaneously, these sites are sensitive to mechanical stimulation and local catecholamines, and are capable of generating prolonged discharges. Sprouting of sympathetic nerves into dorsal root ganglia may provide another mechanism for sympathetically maintained pain.

Peripheral nerve injury also generates secondary central sensitization at the spinal cord level due to excitatory and inhibitory mechanisms. Prolonged and repetitive discharges in primary afferent neurons produces progressive increases in dorsal horn neuronal discharges that can become autonomous. This is a major cause of central sensitization and is referred to as 'wind-up' in the dorsal horn. This phenomenon is mediated by the release of excitatory neurotransmitters, such as glutamate, from the primary afferent terminal and is facilitated by upregulation of voltage-gated calcium channels responsible for neurotransmitter release (11). Glutamate acts on various receptors in the dorsal horn, including the N-methyl-D-aspartate (NMDA) receptor, to produce central sensitization. Allodynia and hyperpathic phenomena such as temporal and spatial summation can be explained by the convergence of low threshold sensory afferents on sensitized wide dynamic range dorsal horn neurons. Conversely, actual transection of primary afferent neurons may reduce the amount of inhibitory input to the spinal cord and lead to dorsal horn hyperexcitability through deafferentation. The fact that there are multiple generators of neuropathic pain following nerve injury provides a rationale for polypharmacy rather than monotherapy in the management of neuropathic pain, because it may be necessary to target several pain mechanisms. It is also clear that none of the generators of neuropathic pain are disease-specific.

\section{DIFFERENTIAL DIAGNOSIS OF NEUROPATHIC PAIN}

The differential diagnoses of neuropathic pain are extensive, and include central and peripheral causes (Table 1). Examples of central neuropathic pain include poststroke pain (thalamic pain syndrome) and pain due to spinal cord injury. Common causes of spinal cord injury may include trauma and the demyelinating lesions of multiple sclerosis. Painful peripheral neuropathy can be divided into focal neuropathies, multifocal neuropathies and symmetrical polyneuropathies.

The diagnosis of neuropathic pain is based primarily on the history and physical examination. Postherpetic neuralgia and painful diabetic neuropathy are usually easy to diagnosis when there is a history of shingles and diabetes mellitus, respectively. However, pain radiating into an extremity can be either referred myofascial or neuropathic pain, and can be difficult to differentiate. A 10-item questionnaire based on sensory descriptors and sensory examination has been developed to differentiate between somatic and neuropathic pain. This instrument has been shown to be a valid and reliable discriminator of neuropathic pain (12). In addition, the presence of true weakness (sometimes difficult to differentiate from pain-related or antalgic weakness), dropped reflexes, allodynia and hyperalgesia

\begin{tabular}{|c|c|}
\hline Class & Examples \\
\hline \multicolumn{2}{|l|}{ Central } \\
\hline Brain & Poststroke pain \\
\hline \multirow[t]{3}{*}{ Spinal cord } & Post-traumatic injury \\
\hline & Multiple sclerosis \\
\hline & Syringomyelia \\
\hline \multicolumn{2}{|l|}{ Peripheral } \\
\hline \multirow[t]{4}{*}{ Focal } & Trigeminal neuralgia \\
\hline & Carpal tunnel syndrome \\
\hline & Failed back syndrome with nerve root fibrosis \\
\hline & Postherpetic neuralgia \\
\hline \multirow[t]{3}{*}{ Multifocal } & Vasculitis \\
\hline & Diabetes mellitus \\
\hline & Brachial or lumbar plexitis \\
\hline \multirow[t]{5}{*}{ Symmetrical } & Diabetes mellitus \\
\hline & Ethanol abuse \\
\hline & Renal failure \\
\hline & Toxins (eg, vincristine) \\
\hline & Amyloidosis \\
\hline
\end{tabular}

would all favour a diagnosis of neuropathic pain. Electromyography and nerve conduction studies are sometimes useful to provide more objective evidence of nerve injury. Imaging, such as computed tomography and magnetic resonance imaging, can confirm the presence of structural disease involving one or more nerve roots or the brachial or lumbosacral plexus. It is important to diagnose structural disease. For instance, nerve root impingement from disc herniation may be amenable to surgical decompression. Tumour infiltration of nerve often responds to targeted radiation therapy.

\section{PHARMACOLOGICAL MANAGEMENT OF NEUROPATHIC PAIN}

Because neuropathic pain is usually unrelenting, treatment goals have to be realistic. It is important to convey to the patient that the primary goal in most cases is to bring the pain into a tolerable range, not to eliminate the pain. It is also important to recognize and treat common comorbidities such as anxiety and depression. All of this targets the importance of secondary treatment goals of improved sleep and function, and overall improvement in quality of life.

Given that there are multiple generators of neuropathic pain that can vary from patient to patient and from one disease to the next, it follows that treatment must be individualized and that two or three agents may be required to target different pain mechanisms. However, decisions regarding first-and second-line drugs are still based on high-quality evidence of efficacy, side effect profile and cost-effectiveness. Because there is a lack of head-to-head trials to guide treatment choices, relative evidence of efficacy and safety can be gleaned from number needed to treat (NNT), the reciprocal of absolute risk reduction. NNT is defined as the number of patients that need to be treated with a certain drug to obtain one patient with at least $50 \%$ pain relief.

\section{Antidepressants}

Tricyclic antidepressants provide the best evidence of efficacy in the management of neuropathic pain. Although the definitive 
mechanism of action of tricyclic analgesia is unknown, these drugs block the reuptake of noradrenaline and serotonin, block hyperalgesia induced by NMDA antagonists and also have sodium channel blocking properties (13). The tricyclics therefore have analgesic properties independent of their antidepressant effects.

Two systematic reviews $(14,15)$ of antidepressants in neuropathic pain revealed a total of 17 randomized, controlled trials (RCTs) involving 10 antidepressants. The NNT was approximately three. There was no difference in NNT between tricyclic antidepressants with balanced reuptake of inhibition of serotonin and noradrenaline (amitriptyline, imipramine) and those with relatively selective inhibition of noradrenaline uptake (desipramine, nortriptyline). Similarly, in terms of NNT, the efficacy for tricyclic antidepressants was nearly identical regardless of the underlying condition (diabetes mellitus, herpes zoster, traumatic nerve injury or stroke). This suggests that the pathophysiology is similar in these varied conditions and that the etiology does not have a significant impact on therapeutic outcome.

The role of selective serotonin reuptake inhibitors in the management of neuropathic pain is controversial. Fluoxetine was not found to be efficacious in the management of diabetic neuropathy independent of its antidepressant effects (16), but paroxetine (17) and citalopram (18) were. However, the combined NNT for all three studies was 6.7 (19); therefore, selective serotonin reuptake inhibitors do not appear to be as efficacious as tricyclic antidepressants in the management of neuropathic pain.

The newer mixed serotonin noradrenaline reuptake inhibitors (SNRIs), venlafaxine and duloxetine, have an NNT of approximately four, indicating that they are more likely to be effective for neuropathic pain (20).

\section{Anticonvulsants}

Both carbamazepine (21) and phenytoin (22) have been shown to be useful in the management of diabetic neuropathy, with an overall NNT of 2.5 for effectiveness. However, there is only one RCT on each drug and these trials were of limited sample size - 30 patients in the carbamazepine trial and 12 patients in the phenytoin trial. Carbamazepine nevertheless remains the drug of first choice for trigeminal neuralgia with an NNT of 1.7 (20).

Gabapentin is an anticonvulsant that was approved by the United States in 1994 for the management of partial epilepsy. However, it has been used much more frequently in the management of neuropathic pain. Gabapentin is structurally related to gamma-aminobutyric acid (GABA), but it does not clearly have GABA properties. It binds to presynaptic voltage-gated calcium channels, and the mechanism of action is probably related to a reduction of release of excitatory neurotransmitters due to calcium channel blockade (23). There are eight randomized, double-blind, placebo-controlled trials of gabapentin for chronic neuropathic pain (24). The best known of these are two studies examining the management of painful diabetic neuropathy (25) and postherpetic neuralgia (26) using high-quality study designs. In both studies, gabapentin produced significant pain relief relative to placebo and there was also significant improvement in measures of quality of life and mood. The combined NNT for these two studies was approximately four.

Pregabalin is an analogue of gabapentin. It has the same mechanism of action, but manifests linear pharmacokinetics and has higher affinity for the presynaptic calcium channel. Several large RCTs have shown that pregabalin provides significant pain relief and improved quality of sleep in postherpetic neuralgia $(27,28)$, painful diabetic neuropathy $(29-31)$ or both (32). The overall NNT for pregabalin in these conditions is 4.2 (20). Pregabalin has also been studied in chronic central neuropathic pain following spinal cord injury with evidence of significant pain relief (33).

Lamotrigine is a novel anticonvulsant agent that has shown some benefit in the management of neuropathic pain. Lamotrigine may act through voltage-gated cation channels with inhibition of glutamate release. Lamotrigine has been found to be useful in the management of trigeminal neuralgia (34) and painful diabetic neuropathy (35). However, lamotrigine was not found to be useful in the management of a variety of peripheral neuropathic pain states (36). Lamotrigine also requires slow and careful titration and carries a risk of a potentially serious rash, including Stevens-Johnson syndrome.

Topiramate and valproate have produced mixed results in neuropathic pain trials (20).

\section{Opioid analgesics}

There is still considerable controversy surrounding the use of opioid analgesics for chronic neuropathic pain (37). The crucial factor in this controversy is the balance between analgesia and opioid-induced side effects. A pharmacokineticpharmacodynamic analysis of brief opioid infusions suggests that neuropathic pain responds to opioid drugs in a classic dose-dependent fashion, with a shift to the right in the doseresponse curve (38). This contention was supported in a randomized, controlled, postoperative study that examined pain relief after thoracotomy using intravenous buprenorphine (39). The primary outcome measure was $50 \%$ pain relief. Pain relief was assessed in the immediate postoperative period when the pain was largely nociceptive, and at one month after surgery in the same 21 patients who developed post-thoracotomy neuropathic pain. The dose of buprenorphine required to provide $50 \%$ pain relief for neuropathic pain was almost twice the dose required for nociceptive pain.

A recent systematic review of high-quality RCTs involving eight studies lasting up to eight weeks each demonstrated clinically important efficacy (40). These studies demonstrated, on average, a $20 \%$ to $30 \%$ reduction in pain intensity. RCTs in patients with postherpetic neuralgia given controlled-release oxycodone (41) or controlled-release morphine (42) showed a significant reduction in pain intensity with variable improvement in sleep and disability. Trials of controlled-release oxycodone in painful diabetic neuropathy showed more consistent improvement in pain, sleep and ability to function $(43,44)$.

Tramadol is a unique analgesic agent that mimics some of the properties of tricyclic antidepressants in that it inhibits reuptake of noradrenaline and serotonin. Tramadol also shows low-affinity binding for the $\mu$ opioid receptor, which allows it to be a weak opioid agonist (45). Tramadol has been studied in three RCTs involving patients with painful diabetic neuropathy and mixed neuropathic pain syndromes, and provides an overall NNT of 3.9 (20).

Methadone is a synthetic opioid analgesic that may be particularly useful in the management of neuropathic pain due to its NMDA antagonist properties (46). Methadone is also attractive because it has excellent oral bioavailability, duration of action of at least $8 \mathrm{~h}$ with repetitive dosing and availability 
at very low cost. However, it has an elimination half-life of $24 \mathrm{~h}$ to $36 \mathrm{~h}$, which requires close observation during the titration phase. There are two small RCTs demonstrating benefit from methadone in chronic neuropathic pain $(47,48)$, and survey data suggest efficacy in mixed neuropathic pain conditions (49).

\section{NMDA antagonists}

NMDA agonists and receptors play a major role in the type of neuronal hyperexcitability of the dorsal horn that has been associated with neuropathic pain. NMDA antagonists may therefore decrease the central sensitization responsible for neuropathic pain. However, NMDA antagonists commonly induce psychomimetic side effects, which can make the therapeutic window for this drug very narrow. Ketamine, a commonly used intravenous anesthetic with NMDA antagonist activity, has shown modest efficacy in several neuropathic pain clinical trials, although the side effects associated with this drug can be dose limiting (50). Dextromethorphan, a common cough suppressant, is another NMDA antagonist that has been studied in several neuropathic pain states, with mixed results (20).

\section{Topical agents}

Drugs that have a local site of action are attractive because there may be no systemic side effects. In a cream form, capsaicin, the pungent component of hot peppers, has produced mixed results in RCTs (20) and some patients report worsening of their pain with local application. Topical lidocaine, a sodium channel blocker, has been shown to be useful in a variety of focal neuropathic pain syndromes with an NNT of 4.4 (20). Although the $5 \%$ lidocaine patch is not available in Canada, the gel or cream at a concentration of $5 \%$ or $10 \%$ can be made up by pharmacists.

Several topical combination products have been evaluated in neuropathic pain. Topical doxepin, capsaicin and their combination showed benefit (51), whereas a trial of topical amitriptyline $2 \%$ and ketamine $1 \%$, used alone or in combination, produced negative results (52).

\section{Miscellaneous drugs}

Lidocaine and mexiletine are class 1B local anesthetic antiarrhythmic agents whose mechanism of action is sodium channel blockade. Local anesthetics suppress ectopic neural pacemaker sites at lower concentrations than are required for conduction block along the nerve, and therefore, may have a prolonged duration of action. An intravenous infusion of lidocaine $5 \mathrm{mg} / \mathrm{kg}$ over $30 \mathrm{~min}$ to $60 \mathrm{~min}$ may produce analgesia that lasts several hours. This response has been the basis for starting an oral sodium channel blocker such as mexiletine, and there is evidence that an intravenous lidocaine infusion can predict subsequent response to oral mexiletine (53). However, mexiletine has produced positive results in only two of seven neuropathic pain trials (20). Clonidine, an alpha-2 agonist sympathetic blocker, showed benefit in a painful diabetic neuropathy study using an enriched enrollment design (54). Baclofen is a muscle relaxant that may be a useful second-line drug for trigeminal neuralgia (55).

The cannabinoids are analgesic agents with strong evidence of efficacy in animal models and increasing evidence of efficacy in neuropathic pain states. Dronabinol produced modest analgesia in a trial of central pain in multiple sclerosis (56). A 50:50 mixture of tetrahydrocannabinol and cannabidiol in the form of an oral mucosal spray provided significant benefit in another trial of central pain in multiple sclerosis (57).

\section{CLINICAL GUIDELINES IN THE MANAGEMENT OF NEUROPATHIC PAIN}

Beyond NNT analysis, there is very little information to guide evidence-based sequential trials of analgesic agents in the management of chronic neuropathic pain. There have been two randomized comparisons of an antidepressant with an anticonvulsant. The earlier trial, involving central post-stroke pain, showed greater benefit with amitriptyline relative to carbamazapine (58). A more recent crossover trial, comparing amitriptyline with gabapentin in 25 patients with painful diabetic neuropathy, found no difference in analgesic efficacy or side effects (59). However, this study was probably underpowered, so it is difficult to draw any firm conclusions. Therefore, tricyclic antidepressants, the SNRIs, gabapentin and pregabalin are all considered to be first-line agents in the management of chronic neuropathic pain. It is reasonable to initiate treatment with either an antidepressant, or an anticonvulsant such as gabapentin or pregabalin. The tricylic antidepressants appear slightly more efficacious and much less expensive than SNRIs, but have a more challenging side effect profile and are relatively contraindicated in patients with significant cardiovascular disease. Gabapentin and pregabalin appear similar in mechanism of action, efficacy and side effect profile. Pregabalin carries the advantages of twice daily dosing and linear pharmacokinetics relative to gabapentin. If an antidepressant fails, switch to an anticonvulsant or vice versa. Carbamazepine is considered to be a second-line anticonvulsant because it has enzyme-inducing properties that can interfere with other drugs, and evidence of efficacy is not as good as for the newer anticonvulsants, except for trigeminal neuralgia.

Topical lidocaine is probably the drug of first choice for an elderly patient with a focal painful neuropathy such as postherpetic neuralgia, because side effects are usually negligible. When all first-line medications have failed, tramadol (available in Canada combined with acetaminophen as Tramacet [Janssen-Ortho Inc, Canada]) may be useful. Failure of tramadol necessitates a trial of a major opioid analgesic. In fact, it is reasonable to initiate a short-acting opioid such as oxycodone with acetaminophen (Percocet, Bristol-Myers Squibb Canada) for breakthrough pain during titration of first-line agents. If one or more adjuvant analgesics provide adequate pain relief, the requirement for breakthrough medication should decrease. On the other hand, if there is no response to adjuvant analgesics, the total daily dose of the short-acting opioid provides guidance as to the initial maintenance dose in switching to a controlled-release opioid analgesic. Particularly intractable pain may require treatment with an antidepressant, an anticonvulsant and an opioid analgesic. Support for combination pharmacotherapy comes from a recent study reporting enhanced analgesia with a morphine-gabapentin combination relative to either drug alone (60). Table 2 provides dosing regimens for selected agents for neuropathic pain.

\section{INVASIVE TECHNIQUES IN THE MANAGEMENT OF NEUROPATHIC PAIN}

Interventional techniques for pain management are usually considered when standard pharmacological treatments fail and psychological screening shows emotional stability. However, interventional techniques are costly and labour intensive. 


\section{TABLE 2}

Dosing regimens of selected agents for neuropathic pain

\begin{tabular}{|c|c|c|c|c|}
\hline Agent & Starting dose and titration & Usual maintenance dose & Adverse effects & Comments \\
\hline \multicolumn{5}{|c|}{ Tricyclic antidepressants } \\
\hline $\begin{array}{l}\text { Amitriptyline } \\
\text { Nortriptyline } \\
\text { Desipramine } \\
\text { Imipramine }\end{array}$ & $\begin{array}{l}10 \mathrm{mg} / \text { day to } 25 \mathrm{mg} / \mathrm{day} \text {. } \\
\text { Increase weekly by } \\
10 \mathrm{mg} / \text { day }\end{array}$ & $50 \mathrm{mg} / \mathrm{day}$ to $150 \mathrm{mg} / \mathrm{day}$ & $\begin{array}{l}\text { Drowsiness, confusion, } \\
\text { orthostatic hypotension, } \\
\text { dry mouth, constipation, } \\
\text { urinary retention, weight } \\
\text { gain, arrhythmia }\end{array}$ & $\begin{array}{l}\text { Amitriptyline is more likely to produce } \\
\text { drowsiness and anticholinergic side effects. } \\
\text { Contraindicated in patients with glaucoma } \\
\text { and significant cardiovascular disease }\end{array}$ \\
\hline \multicolumn{5}{|l|}{ Anticonvulsants } \\
\hline Gabapentin & $\begin{array}{l}300 \text { mg/day. Increase } \\
\text { weekly by } 300 \mathrm{mg} / \text { day }\end{array}$ & $\begin{array}{l}300 \mathrm{mg} \text { to } 1200 \mathrm{mg} \text { three } \\
\text { times daily }\end{array}$ & $\begin{array}{l}\text { Drowsiness, dizziness, } \\
\text { peripheral edema, } \\
\text { visual blurring }\end{array}$ & Dosage adjustments required in renal failure \\
\hline Pregabalin & $\begin{array}{l}75 \mathrm{mg} / \text { day to } 150 \mathrm{mg} / \text { day. } \\
\text { Increase weekly by } \\
50 \mathrm{mg} / \text { day to } 150 \mathrm{mg} / \text { day }\end{array}$ & $\begin{array}{l}150 \mathrm{mg} \text { to } 300 \mathrm{mg} \\
\text { twice daily }\end{array}$ & $\begin{array}{l}\text { Drowsiness, dizziness, } \\
\text { peripheral edema, } \\
\text { visual blurring }\end{array}$ & Similar adjustments in renal failure \\
\hline Carbamazepine & $\begin{array}{l}100 \mathrm{mg} \text { once daily. Increase } \\
\text { weekly by } 100 \mathrm{mg} / \text { day to } \\
200 \mathrm{mg} / \text { day }\end{array}$ & $\begin{array}{l}200 \mathrm{mg} \text { to } 400 \mathrm{mg} \text { three } \\
\text { times daily }\end{array}$ & $\begin{array}{l}\text { Drowsiness, dizziness, } \\
\text { blurred, vision, ataxia, } \\
\text { headache, nausea, rash }\end{array}$ & $\begin{array}{l}\text { As an enzyme inducer, may interfere with } \\
\text { activity of other drugs like warfarin. } \\
\text { Monitoring of blood counts and liver } \\
\text { function tests are recommended }\end{array}$ \\
\hline \multicolumn{5}{|c|}{ Controlled-release opioid analgesics } \\
\hline $\begin{array}{l}\text { Morphine } \\
\text { Oxycodone } \\
\text { Fentanyl }\end{array}$ & $\begin{array}{l}15 \mathrm{mg} \text { every } 12 \mathrm{~h} \\
10 \mathrm{mg} \text { every } 12 \mathrm{~h} \\
25 \mu \mathrm{g} / \mathrm{h} \text { patch }\end{array}$ & $\begin{array}{l}30 \mathrm{mg} \text { to } 120 \mathrm{mg} \text { every } 12 \mathrm{~h} \\
20 \mathrm{mg} \text { to } 60 \mathrm{mg} \text { every } 12 \mathrm{~h} \\
25 \mu \mathrm{g} / \mathrm{h} \text { to } 100 \mu \mathrm{g} / \mathrm{h} \text { patch }\end{array}$ & $\begin{array}{l}\text { Nausea, vomiting, sedation, } \\
\text { dizziness, urinary retention, } \\
\text { constipation }\end{array}$ & $\begin{array}{l}\text { Constipation requires concurrent bowel } \\
\text { regimen. Addiction is unusual unless there } \\
\text { is a history of substance abuse }\end{array}$ \\
\hline \multicolumn{5}{|l|}{ Others } \\
\hline Tramadol & $\begin{array}{l}50 \mathrm{mg} / \text { day. Increase } \\
\text { weekly by } 50 \mathrm{mg} / \text { day }\end{array}$ & $\begin{array}{l}50 \mathrm{mg} \text { to } 150 \mathrm{mg} \text { four } \\
\text { times daily }\end{array}$ & $\begin{array}{l}\text { Nausea, constipation, } \\
\text { somnolence, headache }\end{array}$ & $\begin{array}{l}\text { May lower seizure threshold - use with } \\
\text { caution in epilepsy. In combination with } \\
\text { acetaminophen, keep maximal dose of } \\
\text { acetaminophen at } 4 \mathrm{~g} \text { to avoid } \\
\text { hepatic toxicity }\end{array}$ \\
\hline Lidocaine & $\begin{array}{l}5 \% \text { patches applied for } 12 \mathrm{~h} \\
\text { in a } 24 \mathrm{~h} \text { period }\end{array}$ & & & $\begin{array}{l}\text { Probable agent of first choice for } \\
\text { postherpetic neuralgia. Virtually no } \\
\text { systematic side effects }\end{array}$ \\
\hline
\end{tabular}

Continuous spinal infusion of an opioid or clonidine via an implantable pump may be salutary (61). Longitudinal studies of spinal cord stimulation have consistently shown significant pain relief in $50 \%$ to $60 \%$ of patients with neuropathic pain (62) affecting the extremities. The stimulation must cover the area of pain and, if the electrodes migrate, pain control may be lost necessitating surgical revision.

\section{PREVENTION OF NEUROPATHIC PAIN AND NEW TREATMENT STRATEGIES}

Presently, only approximately $50 \%$ of patients realize adequate relief from neuropathic pain (5). Preventive techniques and novel treatment strategies are obviously needed to improve outcome. The use of antiviral drugs in the first $72 \mathrm{~h}$ following development of a zoster rash does not reliably prevent postherpetic neuralgia, but can decrease the prevalence of pain at six months postinfection by $50 \%$ (63). A recent RCT involving a zoster vaccine reduced the incidence of postherpetic neuralgia by two-thirds, but this is a long-term treatment strategy that would require a massive vaccination program and evaluation of cost-effectiveness (64).

There are likely genetic determinants of neuropathic pain that target those individuals who are at greatest risk following nerve injury. Identification of these patients may allow more aggressive early management of this patient population (65). There is emerging evidence that nerve injury results in microglial activation in the dorsal horn. This triggers the release of pronociceptive cytokines, including neurotrophic factors, that can enhance nociceptive transmission and central sensitization. A specific cytokine antagonist may prevent the development of neuropathic pain (66).

\section{SUMMARY}

The present review summarizes the epidemiology, clinical features, pathophysiology, differential diagnosis and management of neuropathic pain. It specifically details an evidencebased approach to the pharmacological management of this disabling condition. Antidepressants and anticonvulsants provide firstline treatments for neuropathic pain. Topical lidocaine is sometimes useful for focal neuropathies such as postherpetic neuralgia. When adjuvant analgesics fail, opioid analgesics are important avenues of treatment. Pharmacological treatments provide adequate pain relief in approximately $50 \%$ of cases. Prevention strategies and novel treatment approaches are required to improve our management of neuropathic pain. 


\section{REFERENCES}

1. Merskey H, Bogduk N, eds. Classification of Chronic Pain: Descriptions of Chronic Pain Syndromes and Definitions of Pain Terms, 2nd edn. Seattle: IASP Press, 1994:209-14.

2. Max MB, Schafer SC, Culnane M, Dubner R, Gracely RH. Association of pain relief with drug side effects in postherpetic neuralgia: A single dose study of clonidine, codeine, ibuprofen, and placebo. Clin Pharmacol Ther 1988;43:363-71.

3. Low PA. Symptomatic treatment of painful neuropathy. JAMA 1998;280:1863-4

4. Stevens PE, Dibble SL, Miaskowski C. Prevalence, characteristics, and impact of postmastectomy pain syndrome: An investigation of women's experiences. Pain 1995;61:61-8.

5. Foley KM. Opioids and chronic neuropathic pain. N Engl J Med 2003;348:1279-81.

6. Bennett GJ. Neuropathic pain: New insights, new interventions. Hosp Pract 1998;33:95-8, 101-4.

7. Herbst RS, Bajorin DF, Bleiberg H, et al. Clinical cancer advances 2005: Major research advances in cancer treatment, prevention and screening - a report from the American Society of Clinical Oncology. J Clin Oncol 2006:24:190-205.

8. Harden RN, Bruehl SP. Diagnostic criteria: The statistical derivation of the four criterion factors. CRPS: Current diagnosis and therapy. In: Wilson P, Stanton-Hicks M, Harden RN, eds. Progress in Pain Research and Management. Seattle: IASP Press, 2005;32:45-58.

9. Woolf CJ, Mannion RD. Neuropathic pain: Aetiology, symptoms, mechanisms and management. Lancet 1999;353:1959-64.

10. Devor M, Lomazov P, Matzner O. Sodium channel accumulation in injured axons as a substrate for neuropathic pain. In: Boivie J, Hansson P, Lindblom U, eds. Progress in Pain Research and Management. Seattle: IASP Press, 1994;3:207-30.

11. Matthews EA, Dickenson AH. Effects of spinally delivered N- and P-type voltage-dependent calcium channel antagonists on dorsal horn neuronal responses in a rat model of neuropathy. Pain 2001,92:235-46.

12. Bouhassira D, Attal N, Alchaar H, et al. Comparison of pain syndromes associated with nervous or somatic lesions and development of a new neuropathic pain diagnostic questionnaire (DN4). Pain 2005,114:29-36.

13. Kingery WS. A critical review of controlled clinical trials for peripheral neuropathic pain and complex regional pain syndromes. Pain 1997;73:123-39.

14. McQuay JH, Tramer M, Nye BA, et al. A systematic review of antidepressants in neuropathic pain. Pain 1996;68:217-27.

15. Sindrup SH, Jensen TS. Pharmacologic treatment of pain in polyneuropathy. Neurology 2000;55:915-20.

16. Max MB, Lynch SA, Muir J, et al. Effects of desipramine, amitriptyline and fluoxetine on pain in diabetic neuropathy. N Engl J Med 1992;326:1250-6.

17. Sindrup SH, Gram LF, Brsen K, et al. The selective serotonin reuptake inhibitor paroxetine is effective in the treatment of diabetic neuropathy symptoms. Pain 1990;42:135-44.

18. Sindrup SH, Bjerre U, Dejgaard A, et al. The selective serotonin uptake inhibitor citalopram relieves the symptoms of diabetic neuropathy. Clin Pharmacol Ther 1992;52:547-52.

19. Sindrup SH, Jensen TS. Efficacy of pharmacological treatments of neuropathic pain: An update and effect related to mechanism of drug action. Pain 1999;83;389-400.

20. Finnerup NB, Otto M, McQuay HJ, et al. Algorithm for neuropathic pain treatment: An evidence-based proposal. Pain 2005;118:289-305.

21. Rull JA, Quibrera R, Gonzalez-Millan H, et al. Symptomatic treatment of peripheral diabetic neuropathy with carbamazepine (Tegretol): Double-blind crossover trial. Diabetologia 1969;5:215-8.

22. Chadda VS, Mathur MS. Double-blind study of the effects of diphenylhydantoin sodium on diabetic neuropathy. J Assoc Physicians India 1978;26:403-6.

23. Bryans JS, Wustrow DJ. 3-substituted GABA analogs with central nervous system activity: A review. Med Res Rev 1999;19:149-77.

24. Dworkin RH, Backonja M, Rowbotham MC, et al. Advances in neuropathic pain. Arch Neurology 2003;60:1524-34.

25. Backonja M, Beydoun A, Edwards KR, et al. Gabapentin for the symptomatic treatment of painful diabetic neuropathy in patients with diabetes mellitus. JAMA 1998;280:1831-6.

26. Rowbotham MC, Harden N, Stacey B, et al. Gabapentin for the treatment of postherpetic neuralgia. JAMA 1998;280:1837-42.
27. Dworkin RH, Corbin AE, Young JP Jr, et al. Pregabalin for treatment of postherpetic neuralgia: A randomized, placebo-controlled trial. Neurology 2003;60:1274-83.

28. Sabatowski R, Galvez R, Cherry DA, et al. 1008-045 Study Group. Pregabalin reduces pain and improves sleep and mood disturbances in controlled clinical trial. Pain 2004;109:26-35.

29. Richter RW, Portenoy R, Sharma U, Lamoreaux L, Bockbrader H, Knapp LE. Relief of painful diabetic peripheral neuropathy with pregabalin: A randomized, placebo-controlled trial. J Pain 2005;6:253-60

30. Lesser H, Sharma U, LaMoreaux L, Poole RM. Pregabalin relieves symptoms of painful diabetic neuropathy: A randomized controlled trial. Neurology 2004;63:2104-10.

31. Rosenstock J, Tuchman M, LaMoreaux L, Sharma U. Pregabalin for the treatment of painful diabetic peripheral neuropathy: A doubleblind, placebo-controlled trial. Pan 2004:110:628-38.

32. Freynhagen R, Strojek K, Griesing T, Whalen E, Balkenohl M. Efficacy of pregabalin in neuropathic pain evaluated in a 12-week, randomized, double-blind, multicentre, placebo-controlled trial of flexible- and fixed-dose regimens. Pain 2005;115:254-63.

33. Siddall J, Cousins MJ, Otte A, et al. Pregabalin safely and efficaciously treats chronic central neuropathic pain after spinal cord injury. J Pain 2005;6:S25.

34. Lunardi G, Leandri M, Albano C, et al. Clinical effectiveness of lamotrigine and plasma levels in essential and symptomatic trigeminal neuralgia. Neurology 1997;48:1714-7.

35. Eisenberg E, Luria Y, Braker C, Daoud D, Ishay A. Lamotrigine reduces painful diabetic neuropathy: A randomized, controlled study. Neurology 2001;57:505-9.

36. McCleane G. $200 \mathrm{mg}$ daily of lamotrigine has no analgesic effect in neuropathic pain: A randomized, double-blind, placebo-controlled trial. Pain 1999;83:105-7.

37. Dellmijn PLI. Are opioids effective in relieving neuropathic pain? Pain 1999;80:453-62.

38. Portenoy RK, Foley KM, Inturissi CE. The nature of opioid responsiveness and its implications for neuropathic pain: New hypotheses derived from studies of opioid infusions. Pain 1990;43:273-86.

39. Benedetti F, Vighetti S, Amanzio M, et al. Dose-response relationship of opioids in nociceptive and neuropathic postoperative pain. Pain 1998;74:205-11.

40. Eisenberg E, McNicol ED, Carr DB. Efficacy and safety of opioid agonists in the treatment of neuropathic pain of nonmalignant origin. JAMA 2005;293:3043-52.

41. Watson CP, Babul N. Efficacy of oxycodone in neuropathic pain: A randomized trial in postherpetic neuralgia. Neurology 1998;50:1837-41.

42. Raja SN, Haythornthwaite JA, Pappagoallo M, et al. Opioids versus antidepressants in postherpetic neuralgia: A randomized placebocontrolled trial. Neurology 2002;59:1015-21.

43. Gimbel JS, Richards P, Portenoy RK. Controlled-release oxycodone for pain in diabetic neuropathy: A randomized controlled trial. Neurology 2003;60:927-34.

44. Watson CP, Moulin DE, Watt-Watson J, et al. Controlled-release oxycodone relieves neuropathic pain: A randomized, controlled trial in painful diabetic neuropathy. Pain 2003;105:71-8.

45. Abramowicz M. Tramadol - a new oral analgesic. Med Lett Drugs Ther 37,1995:59-60.

46. Gannon C. The use of methadone in the care of the dying. Eur J Palliat Care 1997;4:152-8.

47. Gagnon B, Almahrezi A, Schreier G. Methadone in the treatment of neuropathic pain. Pain Res Manage 2003;8:149-54.

48. Morley JS, Bridson J, Nash TP, et al. Low dose methadone has an analgesic effect in neuropathic pain: A double-blind randomized controlled crossover trial. Palliat Med 2003;17:576-87.

49. Moulin DE, Palma D, Watling C, et al. Methadone in the management of intractable neuropathic noncancer pain. Can J Neurol Sci 2005;32:340-3.

50. Hocking G, Cousins MJ. Ketamine in chronic pain management: An evidence-based review. Anesth Analg 2003;97:1730-9.

51. McCleane G. Topical application of doxepin hydrochloride, capsaicin and a combination of both produces analgesia in chronic human neuropathic pain:

A randomized, double-blind, placebo-controlled study. Br J Clin Pharmacol 2000;49:574-9. 
52. Lynch ME, Clark AJ, Sawynok J, et al. Topical 2\% amitriptyline and $1 \%$ ketamine in neuropathic pain syndromes: A randomized, double-blind, placebo-controlled trial. Anesthesiology 2005; 103:140-6.

53. Galer BS, Harle J, Rowbotham MC. Response to intravenous lidocaine infusion predicts subsequent response to oral mexiletine: A prospective study. J Pain Symptom Manage 1996;12:161-7.

54. Byas-Smith MG, Max MB, Muir J, et al. Transdermal clonidine compared to placebo in painful diabetic neuropathy using a twostage "enriched enrolment" design. Pain 1995;60:267-74.

55. Fromm GH, Terance CF, Chatta AS. Baclofen in the treatment of trigeminal neuralgia. Ann Neurol 1984;15:240-7.

56. Svendsen KB, Jensen TS, Bach FW. The cannabinoid dronabinol reduces central pain in multiple sclerosis. A randomized doubleblind, placebo-controlled crossover trial. BMJ 2004;329:253-61.

57. Rog DJ, Nurmikko TJ, Friede T, et al. Randomized, controlled trial of cannabis-based medicine in central pain in multiple sclerosis. Neurology 2005;65:812-9.

58. Leijon G. Boivie J. Central post-stroke pain: A controlled trial of amitriptyline and carbamazepine. Pain 1989;36:27-36.

59. Morello CM, Leckband SG, Stoner CP, Moorhouse DF, Sahagian GA. Randomized double-blind study comparing the efficacy of gabapentin with amitriptyline on diabetic peripheral neuropathy pain. Arch Intern Med 1999;159:1931-7.

60. Gilron I, Max MB. Combination pharmacotherapy for neuropathic pain: Current evidence and future directions. Expert Rev Neurother 2005;5:823-30.

61. Krames E. Implantable devices for pain control: Spinal cord stimulation and intrathecal therapies. Best Pract Res Clin Anaesthesiol 2002;16:619-49.

62. Carter ML. Spinal cord stimulation in chronic pain: A review of the evidence. Anaesth Intensive Care 2004;32:11-21.

63. Gnann JW, Whitley RJ. Herpes zoster. N Engl J Med 2002;347:340-6

64. Oxman MN, Levin MJ, Johnson GR, et al. A vaccine to prevent herpes zoster and postherpetic neuralgia in older adults. N Engl J Med 2005;352:2271-84.

65. Belfer I, Wu T, Kingman A, Krishnaraju RK, Goldman D, Max MB. Candidate gene studies of human pain mechanisms: Methods for optimizing choice of polymorphisms and sample size. Anesthesiology 2004;100:1562-72.

66. Coull JA, Beggs S, Boudreau D, et al. BDNF from microglia causes the shift in neuronal anion gradient underlying neuropathic pain. Nature 2005;438:923-5. 


\section{ERRATUM}

DE Moulin. The clinical management of neuropathic pain. Pain Res Manage 2006;11(Suppl A):30A-36A.

In this paper, the adverse effects of tramadol in Table 2 were incorrectly attributed to lidocaine. The adverse effects of tramadol should have included nausea, constipation, somnolence and headache. Please visit $<$ www.pulsus.com $>$ to view the corrected version of this paper. Pulsus Group extends apologies to the author for this error. 


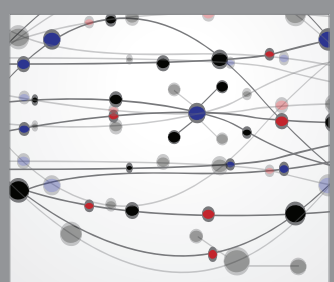

The Scientific World Journal
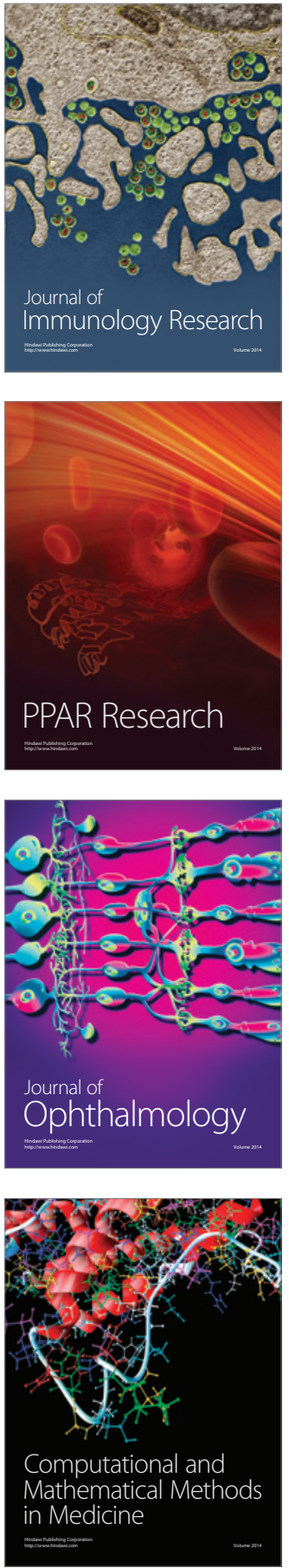

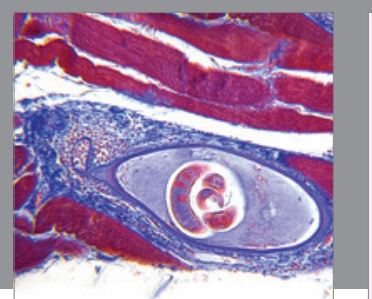

Gastroenterology Research and Practice

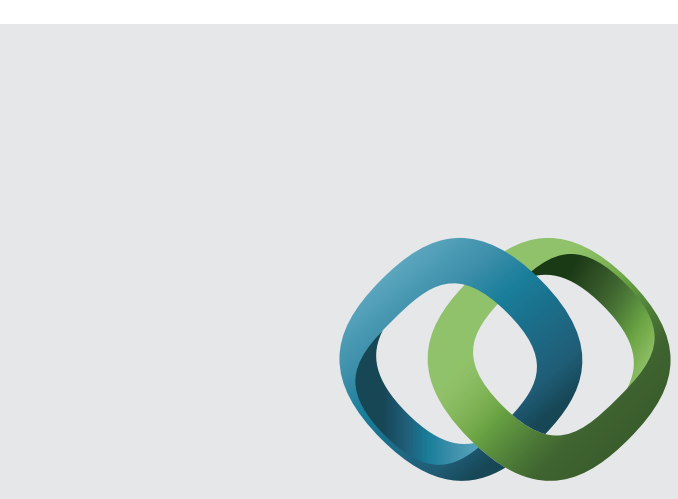

\section{Hindawi}

Submit your manuscripts at

http://www.hindawi.com
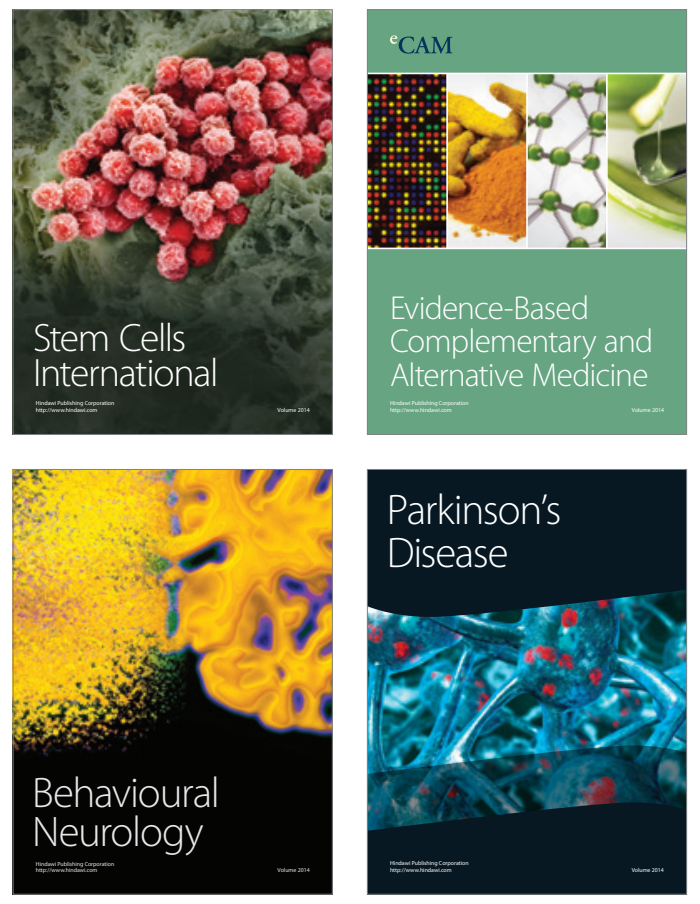
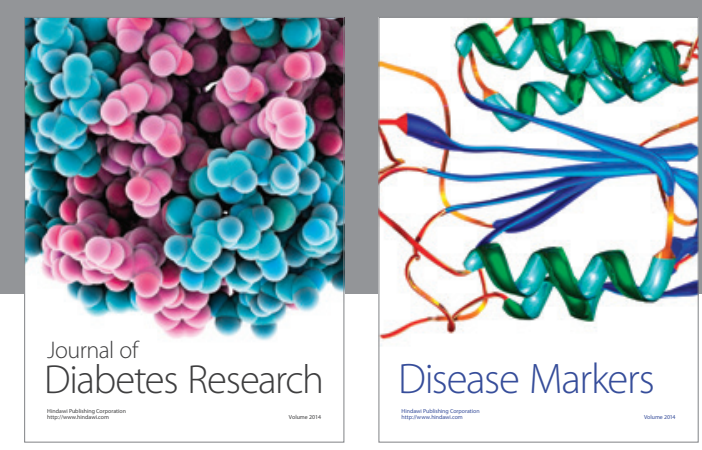

Disease Markers
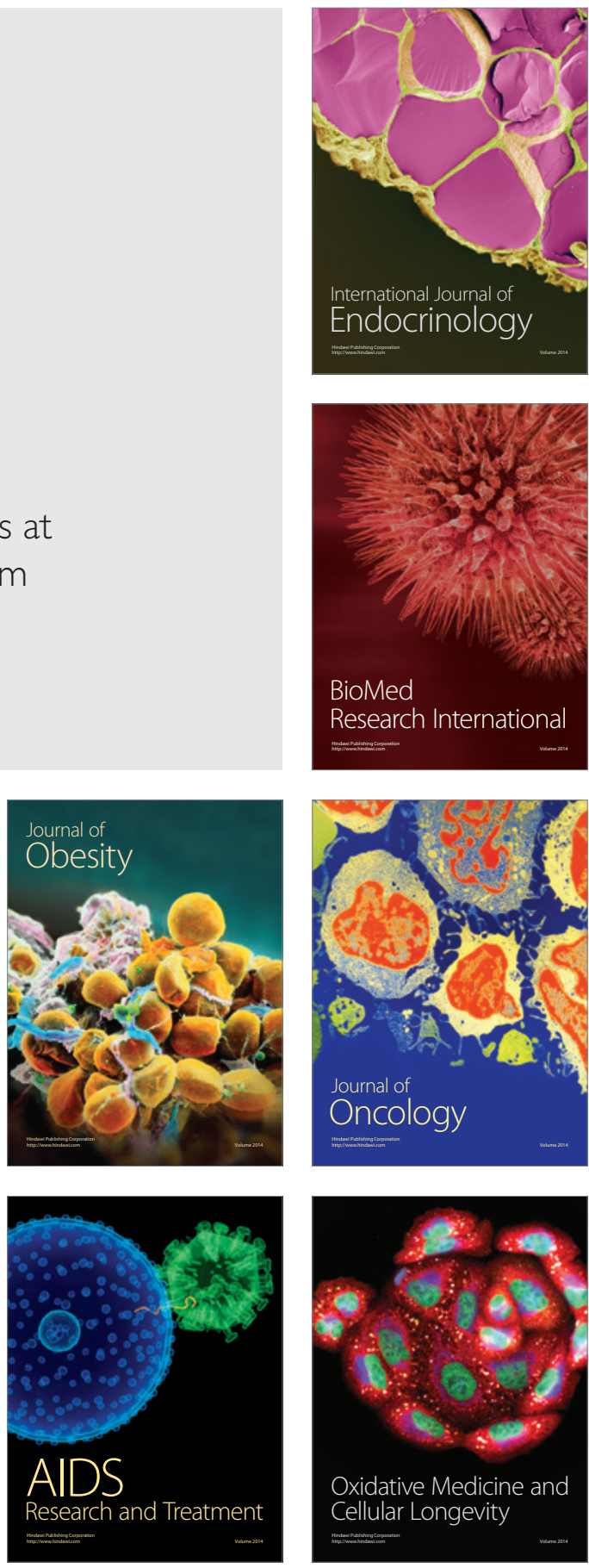